\title{
EFFECT OF DIFFERENT MODELLING APPROACHES ON THE PREDICTION OF THE SEISMIC RESPONSE OF MULTI-STOREY CLT BUILDINGS
}

\author{
LUCA POZZA $^{1}$, MARCO SAVOIA ${ }^{1}$, LUCA FRANCO $^{2}$, ANNA SAETTA $^{2}$ \& DIEGO TALLEDO ${ }^{2}$ \\ ${ }^{1}$ Department of Civil, Chemical, Environmental and Materials Engineering, University of Bologna, Italy. \\ ${ }^{2}$ Department of Architecture Construction and Restoration, University IUAV of Venezia, Italy.
}

\begin{abstract}
This work reports a summary of different type of analyses and modelling approaches, typically adopted by practitioners and researchers for the prediction of the seismic response of multi-storey CLT buildings. Specifically, two different modelling approaches are deeply investigated and compared; the first one is a component approach, which adopts springs (linear or non-linear) for connections, while the second one is based on a simplified phenomenological model where the behaviour of the system is reproduced by means of diagonal springs (linear or non-linear). The advantages and disadvantages of the two approaches are presented and critically discussed with reference to the types of the performed analysis (linear or non-linear).

In order to verify the capability of the two modelling approaches to predict the seismic response of CLT structures performing linear analyses, a series of multi-storey buildings with increasing number of storeys and increasing values of design PGA are investigated. Obtained results are compared in terms of principal elastic periods, internal forces in the connection elements and drifts. Moreover, some correlations between results from the component and the phenomenological approach are given.

Then, a first attempt of defining a numerical model suitable for non-linear analyses of a single CLT shear-wall, according to both the component and the phenomenological approaches is presented. Finally, the obtained results are discussed, highlighting the key issues in non-linear modelling of CLT structures.
\end{abstract}

Keywords: CLT structures, modelling approach, numerical model, seismic design, timber structures

\section{INTRODUCTION}

Multi-storey cross-laminated timber (CLT) buildings have become increasingly common over the last few years, owing to the simplicity and rapid execution of this construction typology, as well as to its high mechanical and physical performance. However, the topic of the modelling and analysis of CLT buildings, especially under seismic actions, is still an hot issue, since the results of the different modelling approaches and type of analyses which can be found in literature demonstrate to be quite heterogeneous and do not allow to draw reliable findings and outcomes.

It is worth nothing that CLT building response under earthquake has been widely studied through experimental tests and numerical simulations in last years. The most comprehensive research on seismic behaviour of low- and mid-rise CLT buildings has been carried out by CNR-IVALSA in Trento, Italy, under the SOFIE Project $[1,2]$. Using as reference such research, a number of experimental campaigns and numerical studies have been conducted in the years by various research groups. Relevant are the tests conducted at the University of Ljubljana, Slovenia, where the behaviour of 2-D CLT shear walls having various load and boundary conditions was assessed [3]. FPInnovations in Canada has undertaken tests to determine the structural properties and seismic resistance of CLT shear walls and small-scale 3-D structures [4]. Failure mechanism in large shear wall systems have been characterised in multiple studies [5-7]. Connection elements suitable for linking CLT panels together and anchoring them at the bases have been studied, with the aim of developing a capacity based 
design approach for CLT structures [8,9] and to define the tension-shear interaction phenomenon [10].

A number of numerical models has been developed and calibrated on the results obtained by the above-mentioned tests with the aim of reproducing the response of single connection elements $[11,12]$ or more in general of entire CLT shear wall and buildings [12-15]. A detailed description of these numerical model and analyses is reported in section 2 .

Finally, analysing the researches available in literature, it is possible to observe that, in the last years, two different approaches have been mainly used to study the seismic behaviour of CLT buildings. The former is design oriented and the analyses are aimed to provide the necessary parameters and information's for a safe design of low-and mid-rise CLT buildings [16, 17], the latter is research oriented and aimed to understand both the seismic performance and the limits of the structural systems when adopted in mid- and high-rise buildings [18, 19].

The aim of the present work is to contribute in understanding the seismic behaviour of CLT superstructures. Results presented below are obtained from numerical analyses conducted adopting different modelling approaches so as to verify their capability in the prediction of the seismic response of CLT buildings.

\section{OVERVIEW ON MODELLING STRATEGIES FOR CLT BUILDINGS}

CLT buildings can be studied both through linear and non-linear analysis approaches. The first (design-oriented) is usually followed by engineers in the design phase, while the second one (research-oriented) is typically used for research purposes. In both cases, the CLT panelconnection system can be numerically modelled in two different ways: (1) component-level modelling; (2) phenomenological modelling. Peculiarities, advantages and problems related to both modelling approaches are presented in the following.
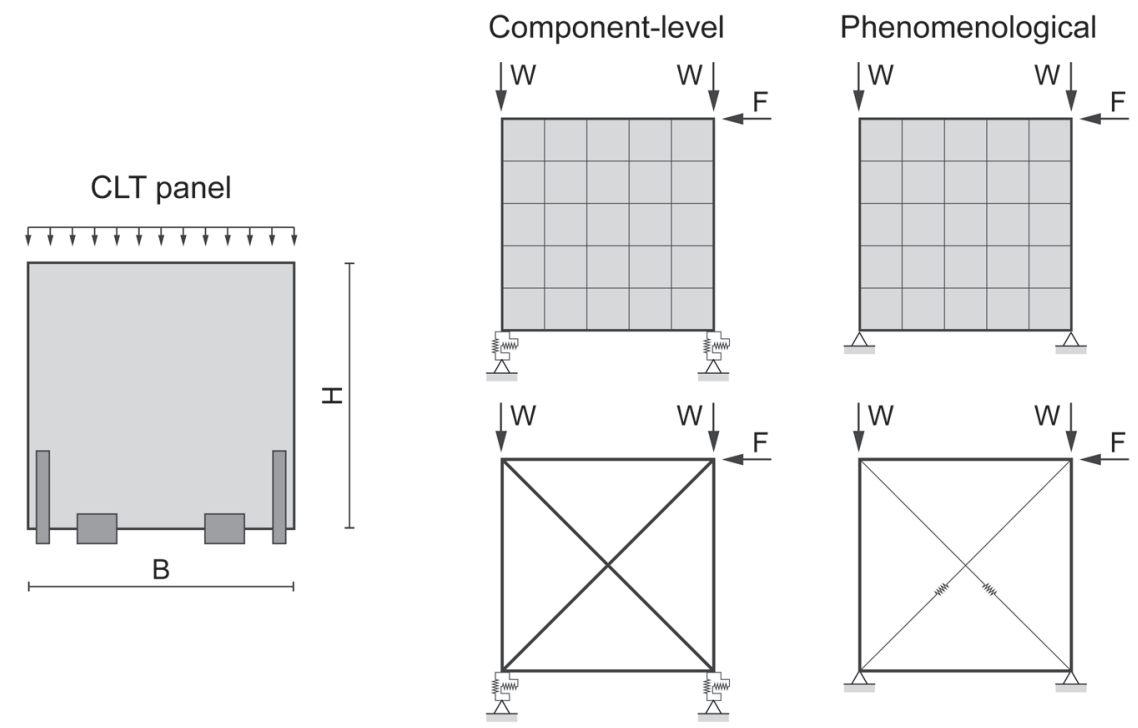

Figure 1: Schematic representation of modelling techniques for a CLT wall: component-level and phenomenological approaches. 


\subsection{Component-level modelling approach}

The component-level modelling approach $[11,12,16]$ is based on the reproduction of the structural response (linear or non-linear) of all the single components of the structural system, i.e. connections and timber panels. This method requires the calibration of the constitutive law for each component based on the results from experimental test or on proper analytical assessments.

Concerning linear analyses, the data required for the component-level approach are:

- CLT panel's elastic mechanical properties (Young and shear modulus);

- elastic stiffness of connections.

Elastic mechanical properties of CLT panels are easily available in literature [5, 7]. These walls are usually modelled as an isotropic material, with an equivalent modulus of elasticity $[13,16]$ given by the weighted mean values of the modulus in the parallel and perpendicular direction to the grain, corresponding to the glued crosswise-alternated timber of the panel. Sometimes an orthotropic material model is adopted, e.g. Ref. [14].

As regards the values of elastic stiffness to be assigned to connections, two different approaches can be adopted. The first one refers to the prescriptions of Eurocode 5 [20] concerning the calculation of the sliding modulus $\left(k_{s e r}\right)$ of a nailed steel-timber connection. The second method is based on the linearization of the force-displacement curve obtained from experimental tests on the single connection elements. Results available in literature [16] show that stiffness estimations obtained using the formulation proposed by Eurocode 5 [20] overestimate the actual elastic stiffness of the connection defined by the experimental tests. This could be ascribed to the fact that they only consider the deformability of cylindrical-stem connectors disregarding that the actual stiffness of the joint is given by the in-series contribution of nailing, metal plate and base anchor [9]. This last aspect represents a strong limitation in the applicability of linear analyses with the component-level approach, since it requires the validation of the analytical stiffness with experimental tests, which are not always available for all type of connectors.

Concerning non-linear analyses, it is well known that non-linearity in CLT structures is due to the connections' behaviour since the timber panel reacts elastically thanks to its high resistance and stiffness. As a consequence, component-level non-linear analysis requires the calibration of the numerical model used to reproduce the non-linear behaviour (monotonic or cyclic) of the connections. It is therefore necessary to define the force-displacement curve that characterizes the behaviour of the connection. This curve can be obtained by experimental tests on single connection or by means of numerical analysis with advanced models able of reproducing the wood-connection interaction [21]. The calibration aims to represent both the backbone curve and the energy dissipation characteristics.

From the above-mentioned issues, it is clear that the component-level modelling generally requires an accurate calibration of the elements that reproduce the structural behaviour of connections (both for linear and nonlinear analyses). Once calibration phase is completed, it is possible to simulate the structural behaviour of any structure assembled with the connections that have been calibrated, regardless of the geometrical configuration of the wall and the connections' arrangement.

It must be underlined that a component-level approach cannot take into account phenomena and second-order effects that occur in the global response in the wall and that don't involve the single component that has been calibrated (e.g. friction forces). 
Moreover, in order to model the actual structural behaviour of every single element, complex numerical models that take into account interaction and coupling effects between forces acting into the connection are necessary $[12,13]$.

\subsection{Phenomenological modelling}

Phenomenological modelling disregards the contribution to the structural response given by each component of the system and aims to reproduce faithfully the global response. In detail, for CLT systems, it aims to reproduce the response of the whole wall or structural system.

Phenomenological modelling suitable for linear analyses is carried out through the calibration of an equivalent elastic modulus to be assigned to the wall, so that the actual displacements of the structural system (derived, for instance, from experimental test or specific analyses with sub-models) are obtained from the numerical model.

Concerning non-linear analyses, phenomenological modelling requires the model to fit the force-displacement curve and the hysteretic behaviour of the wall (e.g. the energy dissipation). The calibration of the equivalent modulus of a wall is generally based on monotonic or cyclic experimental tests on an entire wall. Examples of phenomenological modelling of timber construction systems are given, for e.g. in Ref. [22]. The advantages of the phenomenological modelling mainly regard the simplicity of the modelling that, nevertheless, can simulate the global behaviour of the wall including friction phenomena and second-order effects. Moreover, a global test on the whole wall is sufficient for the calibration of the numerical model, without testing every single component (for timber structures global tests can be easily performed, thanks to the lightness of the specimens and the low forces acting on them). The main drawback of the phenomenological modelling is the representativeness of the model that is limited to the wall's configuration used to develop the model. Therefore, this approach is not suitable to study structural systems composed of walls with different geometrical configuration or connections' arrangement than those used for calibration.

\subsection{Hybrid modelling}

In some cases hybrid modelling techniques can also be used; this technique consists in a component-level approach calibrated on the global wall's structural response. On one hand this modelling technique overcomes the problems highlighted for the component-level approach, since it allows the inclusion in the connection's behaviour of the friction phenomena and the second order effects; on the other hand, it keeps the limitations of the phenomenological approach, i.e. the dependency of the calibration on the geometry and arrangement of the wall. Anyway, the rational use of this modelling technique combined with experimental tests designed ad-hoc allows to obtain a good simulation of the structural response of CLT buildings, as shown by many examples available in the literature [13]. Hybrid modelling technique is not considered in the present work.

\section{CASE-STUDY: LINEAR ANALYSES}

In this work a specific building configuration was investigated through numerical linear analyses. In particular, timber shear-wall, typically used to brace multi-storey CLT buildings, was analysed. The details of the case study, of the numerical model and the main results obtained from the linear analyses are reported in the following. 


\subsection{Parametric analyses}

The parametric analyses were carried out considering as primary variables the number of storeys of the examined building and the seismicity level of the site. In particular, buildings with 2, 4 and 6 storeys were considered, and each of them was analysed with three increasing levels of seismic intensity, respectively represented by $\mathrm{PGA}=0.15 \mathrm{~g}-0.25 \mathrm{~g}-0.35 \mathrm{~g}$, and characterized by the elastic SLS and design ULS spectra according to Italian Buildings' Code [23]). The spectra adopted, together with the main spectral parameters, are depicted in Fig. 2. Table 1 reports, for each considered configuration, the seismic mass at each storey, the corresponding vertical loads and the thickness of the CLT panels.

For each configuration, the connection's arrangement was designed referring to linear static analysis [24] and to the iterative procedure described in Ref. [17]. Since the configuration is regular, a behaviour factor $q=2$ was adopted.

The strength of nailed connections was evaluated according to Johansen theory, as reported in different standards, e.g. Eurocode 5 [20], or in the specific product approval certificates. In order to evaluate the stiffness of connections, both the formulation presented in EC5 [20] for estimation of $k_{s e r}$ and available experimental tests on the same connections [16] were

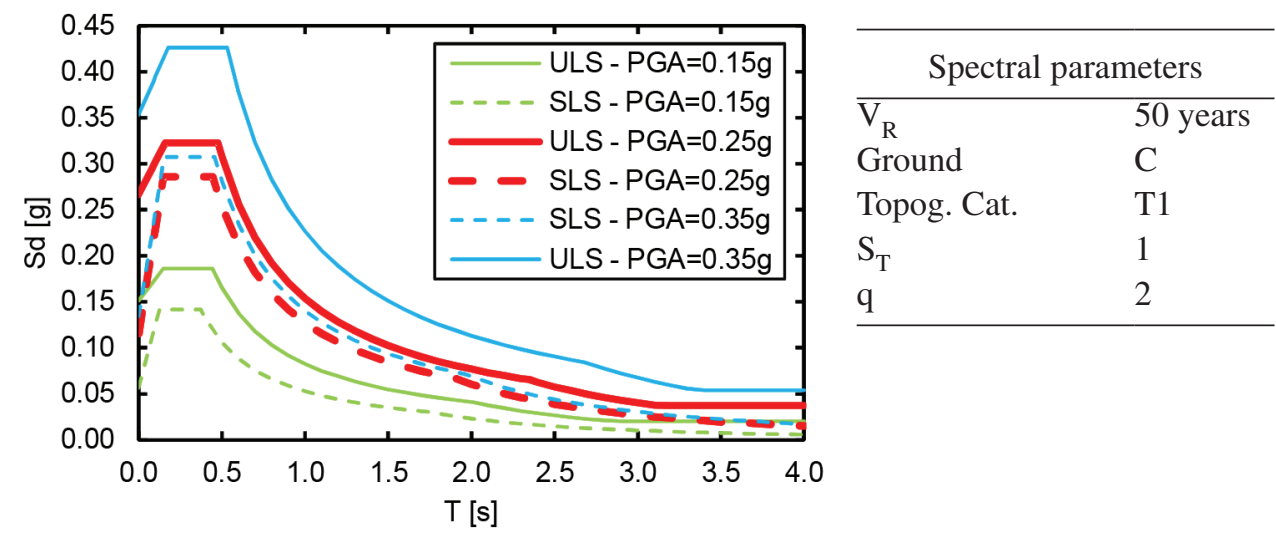

Figure 2: Design spectra for the three seismicity level considered.

Table 1: Seismic mass and vertical load acting at each level for each configuration.

\begin{tabular}{lllllllllll}
\hline & \multicolumn{3}{c}{2 storey } & \multicolumn{3}{c}{ 4 storey } & \multicolumn{7}{c}{ 6 storey } \\
\cline { 2 - 10 } level & M & W & $\mathrm{t}]$ & $\mathrm{M}$ & $\mathrm{W}$ & $\mathrm{t}$ & $\mathrm{M}$ & $\mathrm{W}$ & $\mathrm{t}$ \\
\cline { 2 - 10 } 1 & 28.90 & 18.90 & 100 & 28.90 & 18.90 & 160 & 28.90 & 18.90 & 200 \\
2 & 20.64 & 13.50 & 80 & 28.90 & 18.90 & 120 & 28.90 & 18.90 & 200 \\
3 & $/$ & $/$ & $/$ & 28.90 & 18.90 & 100 & 28.90 & 18.90 & 160 \\
4 & $/$ & $/$ & $/$ & 20.64 & 13.50 & 80 & 28.90 & 18.90 & 120 \\
5 & $/$ & $/$ & $/$ & $/$ & $/$ & $/$ & 28.90 & 18.90 & 100 \\
6 & $/$ & $/$ & $/$ & $/$ & $/$ & $/$ & 20.64 & 13.50 & 80 \\
\hline
\end{tabular}


Table 2: Main mechanical parameters of connections elements.

\begin{tabular}{|c|c|c|c|}
\hline Connector type & $\begin{array}{l}\text { Analytical Load } \\
\text { bearing capacity } \mathrm{F}_{\mathrm{d}}{ }^{*}\end{array}$ & $\begin{array}{l}\text { Analytical elastic } \\
\text { stiffness } k_{\text {ser }}\end{array}$ & 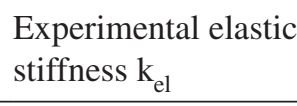 \\
\hline Holdown WHT340 & $42.00 \mathrm{kN}$ & $20987.81 \mathrm{~N} / \mathrm{mm}$ & $5704.81 \mathrm{~N} / \mathrm{mm}$ \\
\hline Holdown WHT440 & $63.40 \mathrm{kN}$ & $31481.72 \mathrm{~N} / \mathrm{mm}$ & $6608.75 \mathrm{~N} / \mathrm{mm}$ \\
\hline Holdown WHT620 & $85.20 \mathrm{kN}$ & $54568.31 \mathrm{~N} / \mathrm{mm}$ & $13247.18 \mathrm{~N} / \mathrm{mm}$ \\
\hline $\begin{array}{l}\text { Angle bracket } \\
\text { TCF200 }\end{array}$ & $22.20 \mathrm{kN}$ & $31481.72 \mathrm{~N} / \mathrm{mm}$ & 8479.13 N/mm \\
\hline $\begin{array}{l}\text { Angle bracket } \\
\text { TTF200 }\end{array}$ & $35.50 \mathrm{kN}$ & $31481.72 \mathrm{~N} / \mathrm{mm}$ & $8211.60 \mathrm{~N} / \mathrm{mm}$ \\
\hline
\end{tabular}

*values obtained assuming $\mathrm{K}_{\bmod }=1.1$ and $\gamma_{\mathrm{M}}=1$

considered. Table 2 reports strength and stiffness values for the connections adopted. It is worth noting that EC5 formulation significantly overestimates the elastic stiffness of the connection [17]. For this reason, the experimental values of stiffness should be adopted for an accurate analysis of a CLT building.

The arrangement of connections (i.e. the type and number of connections at each level) is reported for all the considered configurations in Table 3. It can be observed that the number of connections at the base increases for increasing number of storeys and for increasing level of seismic intensity.

Table 3: Connection pattern at each levels for the considered case studies configurations.

\begin{tabular}{|c|c|c|c|c|c|c|c|}
\hline \multirow[b]{2}{*}{ PGA } & \multirow[b]{2}{*}{ level } & \multicolumn{2}{|l|}{2 storey } & \multicolumn{2}{|l|}{4 storey } & \multicolumn{2}{|l|}{6 storey } \\
\hline & & HD & $\mathrm{AB}$ & HD & $\mathrm{AB}$ & HD & $\mathrm{AB}$ \\
\hline \multirow{6}{*}{ 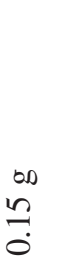 } & 0 & 2 WHT340 & 5 TTF200 & 4 WHT620 & 9 TTF200 & 9 WHT620 & 13 TTF200 \\
\hline & 1 & 1 WHT340 & 5 TCF200 & 3 WHT440 & 8 TTF200 & 7 WHT620 & 13 TTF200 \\
\hline & 2 & I & I & 2 WHT340 & 6 TTF200 & 5 WHT620 & 11 TTF200 \\
\hline & 3 & / & / & 1 WHT340 & 5 TCF200 & 3 WHT620 & 9 TTF200 \\
\hline & 4 & I & I & I & I & 2 WHT440 & 7 TTF200 \\
\hline & 5 & I & I & / & I & 1 WHT340 & 5 TCF200 \\
\hline \multirow{6}{*}{ 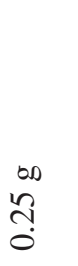 } & 0 & 2 WHT620 & 9 TTF200 & 8 WHT620 & 15 TTF200 & 18 WHT620 & 23 TTF200 \\
\hline & 1 & 2 WHT340 & 8 TCF200 & 5 WHT620 & 14 TTF200 & 14 WHT620 & 22 TTF200 \\
\hline & 2 & I & I & 3 WHT440 & 10 TTF200 & 10 WHT620 & 20 TTF200 \\
\hline & 3 & I & / & 2 WHT340 & 8 TCF200 & 6 WHT620 & 16 TTF200 \\
\hline & 4 & I & / & / & I & 4 WHT440 & 11 TTF200 \\
\hline & 5 & / & / & / & I & 2 WHT340 & 9 TCF200 \\
\hline \multirow{6}{*}{ 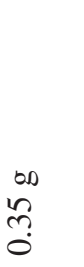 } & 0 & 3 WHT620 & 11 TTF200 & 11 WHT620 & 20 TTF200 & 25 WHT620 & 31 TTF200 \\
\hline & 1 & 2 WHT340 & 10 TCF200 & 7 WHT620 & 18 TTF200 & 19 WHT620 & 29 TTF200 \\
\hline & 2 & I & I & 5 WHT440 & 13 TTF200 & 13 WHT620 & 26 TTF200 \\
\hline & 3 & / & / & 2 WHT340 & 11 TCF200 & 8 WHT620 & 21 TTF200 \\
\hline & 4 & / & / & / & I & 4 WHT620 & 15 TTF200 \\
\hline & 5 & / & I & I & I & 2 WHT440 & 11 TCF200 \\
\hline
\end{tabular}




\subsection{Numerical model}

All the considered configurations were modelled in 2-D according to both a component-level approach and a phenomenological approach. With regards to the former, the connections were modelled with linear elastic springs. As already mentioned, the stiffness of such springs was set as the experimental one, see Table 2. CLT panels were modelled with isoparametric four-node quadrilateral membrane F.E., with an equivalent isotropic material whose mechanical properties were averaged between the longitudinal and transversal direction. The adopted values for elastic parameters are: $\mathrm{E}=5685 \mathrm{MPa}, \mathrm{v}=0.35$.

As for the phenomenological approach, the wall was modelled with the same membrane elements; in this case, an equivalent modulus of elasticity was calibrated in order to capture the deformability of the CLT panel assessed with the component-level approach. In particular, the phenomenological model was calibrated in order to obtain the same horizontal displacements at ULS. The obtained values of the equivalent modulus of elasticity times the wall thickness are reported in Table 4. It is worth noting that these values may represent an useful reference for practitioners that want to adopt a phenomenological approach taking advantage of its simplicity and computational efficiency.

\subsection{Results}

Spectral analyses were carried out for all the configurations considered in the parametric study and for both modelling approaches. The results of such analyses in terms of first period are reported in Table 5 together with the estimation proposed by Eurocode 8 [24]. It can be observed that the two modelling approaches are consistent each other, but for the 4 and 6 storey buildings the values of elastic period $T_{1}$ is much greater than the analytical prediction proposed by EC8 [24]. The difference may be ascribed to the fact that the real deformation of the connections is highly influenced from the stiffness of connections, so that the wall system results much more deformable. A further evidence of this aspect is represented by the decreasing of the difference between $T_{1}$ estimated by numerical analyses and $T_{1}$ evaluated by EC8 [24] for increasing PGA due to the increasing number of connections (i.e. higher stiffness).

Table 4: Equivalent modulus of elasticity for walls of phenomenological model for each configuration and increasing level of PGA.

\begin{tabular}{llllllll} 
PGA & $\begin{array}{l}\mathrm{E}_{\text {eq }} \cdot \mathrm{t} \\
{[\mathrm{N} / \mathrm{mm}]}\end{array}$ & level 1 & level 2 & level 3 & level 4 & level 5 & level 6 \\
\hline $0.15 \mathrm{~g}$ & 2 storey & $5.00 \mathrm{E}+04$ & $4.00 \mathrm{E}+04$ & $\backslash$ & $\backslash$ & $\backslash$ & $\backslash$ \\
& 4 storey & $1.15 \mathrm{E}+05$ & $8.64 \mathrm{E}+04$ & $7.20 \mathrm{E}+04$ & $5.76 \mathrm{E}+04$ & $\backslash$ & $\backslash$ \\
& 6 storey & $1.80 \mathrm{E}+05$ & $2.40 \mathrm{E}+05$ & $2.08 \mathrm{E}+05$ & $1.56 \mathrm{E}+05$ & $1.30 \mathrm{E}+05$ & $5.60 \mathrm{E}+04$ \\
$0.25 \mathrm{~g}$ & 2 storey & $7.50 \mathrm{E}+04$ & $7.60 \mathrm{E}+04$ & $\backslash$ & $\backslash$ & $\backslash$ & $\backslash$ \\
& 4 storey & $1.60 \mathrm{E}+05$ & $1.44 \mathrm{E}+05$ & $1.20 \mathrm{E}+05$ & $1.04 \mathrm{E}+05$ & $\backslash$ & $\backslash$ \\
& 6 storey & $2.50 \mathrm{E}+05$ & $3.00 \mathrm{E}+05$ & $2.56 \mathrm{E}+05$ & $1.92 \mathrm{E}+05$ & $1.60 \mathrm{E}+05$ & $1.04 \mathrm{E}+05$ \\
$0.35 \mathrm{~g}$ & 2 storey & $9.00 \mathrm{E}+04$ & $8.80 \mathrm{E}+04$ & $\backslash$ & $\backslash$ & $\backslash$ & $\backslash$ \\
& 4 storey & $1.92 \mathrm{E}+05$ & $1.56 \mathrm{E}+05$ & $1.40 \mathrm{E}+05$ & $1.20 \mathrm{E}+05$ & $\backslash$ & $\backslash$ \\
& 6 storey & $3.00 \mathrm{E}+05$ & $3.00 \mathrm{E}+05$ & $2.56 \mathrm{E}+05$ & $2.04 \mathrm{E}+05$ & $1.80 \mathrm{E}+05$ & $1.52 \mathrm{E}+05$ \\
\hline
\end{tabular}


Table 5: First period for each configuration analysed.

\begin{tabular}{llllllllll}
\hline $\mathrm{T}_{1}$ & \multicolumn{2}{l}{ PGA=0.15 g } & \multicolumn{3}{c}{ PGA=0.25 g } & \multicolumn{3}{c}{ PGA=0.35 g } \\
\hline$[\mathrm{s}]$ & EC8 & Comp. & Phen. & EC8 & Comp. & Phen. & EC8 & Comp. & Phen. \\
\hline 2 storey & 0.20 & 0.75 & 0.76 & 0.20 & 0.57 & 0.59 & 0.20 & 0.53 & 0.54 \\
4 storey & 0.34 & 1.33 & 1.30 & 0.34 & 1.06 & 1.05 & 0.34 & 0.98 & 0.98 \\
6 storey & 0.46 & 1.83 & 1.81 & 0.46 & 1.59 & 1.58 & 0.46 & 1.51 & 1.50 \\
\hline
\end{tabular}

Table 6 reports the base shear per unit of length obtained for both the component-level and phenomenological approaches. Comparing the shear values, it is possible to observe that the two approaches lead to similar results for all the configurations.

The values of the uplift forces at the base are reported in Table 7. In the case of component-level approach, the uplift force is directly obtained as the internal force of the proper element that represents the connection. On the other hand, for phenomenological models, such value is obtained by integration of tensile stresses at the edge of the wall. For this reason, the internal arm is under-estimated by phenomenological models and the uplift values are significantly higher than those obtained by component-level models.

Finally, Table 8 reports the maximum inter-storey drift corresponding to SLS for all the configurations studied and for both the modelling approaches. Obviously, inter-storey drifts

Table 6: Base shear forces per unit of length for each configuration analysed.

\begin{tabular}{lllllll}
\hline $\mathrm{v}$ & \multicolumn{2}{l}{ PGA=0.15 g } & \multicolumn{2}{l}{ PGA=0.25 } & \multicolumn{2}{l}{ PGA=0.35 g } \\
\hline$[\mathrm{kN} / \mathrm{m}]$ & Comp. & Phen. & Comp. & Phen. & Comp. & Phen. \\
\hline 2 storey & 14.32 & 15.16 & 32.38 & 32.21 & 48.22 & 48.08 \\
4 storey & 21.92 & 22.12 & 43.98 & 45.36 & 62.96 & 66.20 \\
6 storey & 23.96 & 23.61 & 51.82 & 49.10 & 72.60 & 80.33 \\
\hline
\end{tabular}

Table 7: Base uplift forces for each configuration analysed.

\begin{tabular}{lllllll}
\hline $\mathrm{N}$ & \multicolumn{2}{l}{ PGA=0.15 } & \multicolumn{2}{l}{ PGA=0.25 } & \multicolumn{2}{l}{ PGA=0.35 g } \\
\hline$[\mathrm{kN}]$ & Comp. & Phen. & Comp. & Phen. & Comp. & Phen. \\
\hline 2 storey & 18.11 & 34.03 & 90.83 & 170.65 & 191.28 & 318.37 \\
4 storey & 25.16 & 64.17 & 129.09 & 329.23 & 320.02 & 610.03 \\
6 storey & 41.58 & 110.59 & 179.47 & 477.38 & 438.88 & 863.16 \\
\hline
\end{tabular}

Table 8: Maximum inter-storey drift for each configuration analysed.

\begin{tabular}{lllllll}
\hline$\delta \max$ & \multicolumn{2}{l}{ PGA=0.15 g } & \multicolumn{2}{l}{ PGA=0.25 } & \multicolumn{2}{l}{ PGA=0.35 g } \\
\hline$[\%]$ & Comp. & Phen. & Comp. & Phen. & Comp. & Phen. \\
\hline 2 storey & $0.18 \%$ & $0.15 \%$ & $0.35 \%$ & $0.34 \%$ & $0.36 \%$ & $0.35 \%$ \\
4 storey & $0.27 \%$ & $0.25 \%$ & $0.51 \%$ & $0.48 \%$ & $0.52 \%$ & $0.49 \%$ \\
6 storey & $0.29 \%$ & $0.28 \%$ & $0.60 \%$ & $0.56 \%$ & $0.62 \%$ & $0.58 \%$ \\
\hline
\end{tabular}


evaluated according to the two modelling approaches are almost equal since the phenomenological model was calibrated in order to minimize their difference.

\section{CASE-STUDY: NON-LINEAR ANALYSES}

In the present work, a first attempt of defining a numerical model suitable for the non-linear analyses of a single CLT shear-wall was performed. In particular, the CLT shear-wall tested by Gavric et al. [7] was simulated according to both the component and the phenomenological approach. For the former, the single non-linear springs were calibrated referring to the available experimental tests on the connections [9], while for the latter the non-linear springs were calibrated referring to the global response of the wall. The results were discussed and compared highlighting the key issues in non-linear modelling of CLT structures.

\subsection{Numerical model}

The CLT shear-wall was modelled as a plane lattice grid of truss elements (see Fig. 1). The wall was subjected to increasing amplitude top cyclic displacements. The Pinching4 constitutive model, available in OpenSees framework, was adopted for the non-linear springs.

In particular, for the component approach, the single connections were modelled with non-linear zero-length elements and were calibrated referring to the tension and shear behaviour provided by experimental investigations [9]. In particular, the parameters of the constitutive law were evaluated optimizing the shape of the backbone envelope and minimizing the percentage difference between numerical and experimental dissipated energy. Two common modelling strategies were investigated: in the first one the hold-down connections are idealized as subjected only to axial actions (named component- 1 in the following), while angle-brackets only to shear actions; in the second one both hold-down and angle-brackets are supposed to carry both axial and shear actions without considering coupling effects, i.e. considering a rectangle-shaped tension-shear forces limit domain (named component-2 in the following). The constitutive laws calibrated for hold-down and angle-brackets are depicted in Figure 3.

As regards the phenomenological approach, the wall is assumed as fixed at the base and two diagonal non-linear springs are calibrated in order to represent the main characteristics of the global cyclic behaviour of the entire wall, i.e. optimizing the shape of the backbone envelope and minimizing the percentage difference between numerical and experimental dissipated energy.

\subsection{Results}

The results obtained by the three modelling strategies (i.e. component-1, component- 2 and phenomenological) in terms of load-displacement curves are reported in Figure 4 superimposed with experimental results. It is possible to see that component-1 model is not suitable to represent the CLT shear-wall behaviour, both regarding the backbone envelope and the hysteretic cycles. This result is consistent with the model assumption that disregards the tensile load bearing capacity of angle-brackets and the shear load bearing capacity of holddown. On the other hand, the component- 2 model demonstrated to be able to capture the global response of the CLT shear-wall. It is worth noting that more in deep research is needed for this case since the model does not account for the over-strength effects due to friction between panel and foundation while in the same time the reduced load-carrying capacity of 

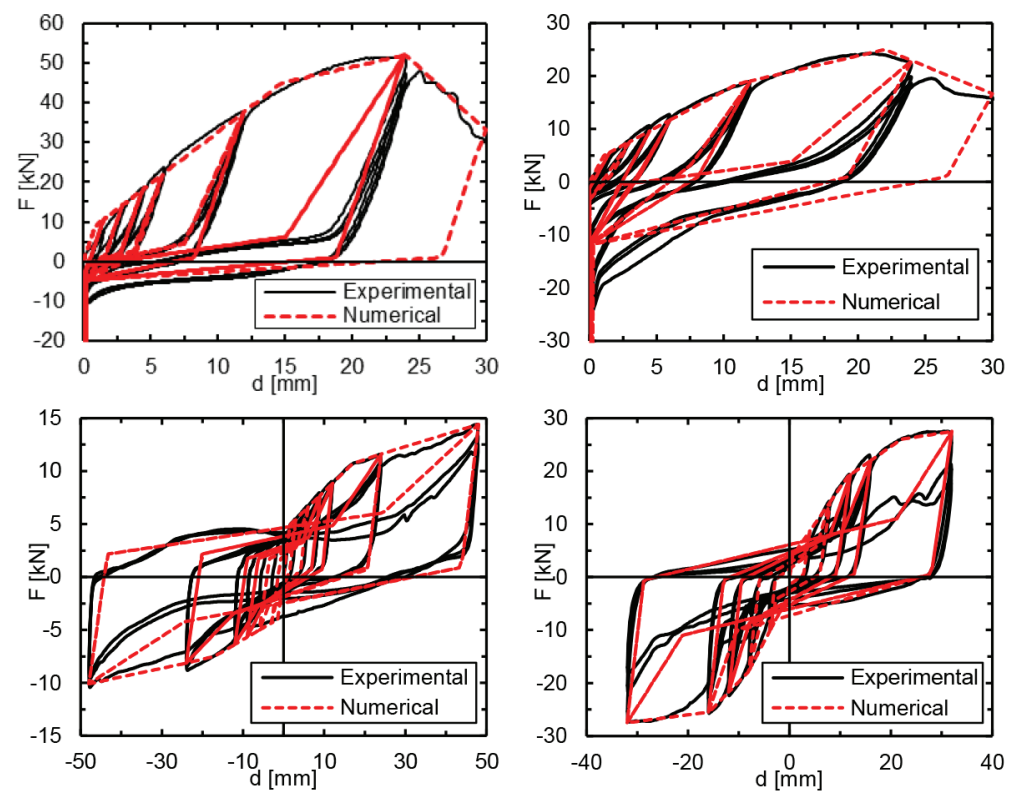

(a)

Figure 3: Calibration of constitutive law for non-linear elements in component approach under: (a) axial and (b) shear actions.

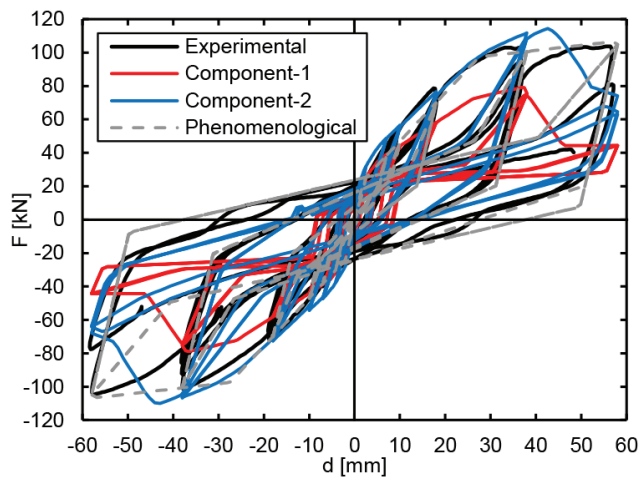

Figure 4: Results of numerical simulations in terms of load-displacement curves compared with experimental data.

the connections due to coupling effects is neglected since it was assumed a rectangular limit domain. These first results seem to show a balance of the two effects.

As expected, the phenomenological model has demonstrated to be able to represent the global response of the wall confirming the capability of the Pinching 4 constitutive law in representing the CLT shear-walls cyclic response.

As a further validation of the component approaches, the local responses of base connections (corner uplift and base slip) provided by numerical analyses are compared with experimental measures. In Figure 5, the corner uplift and base slip values for each load reversal are depicted. 


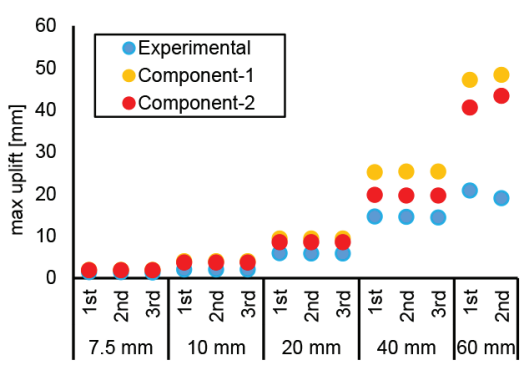

(a)

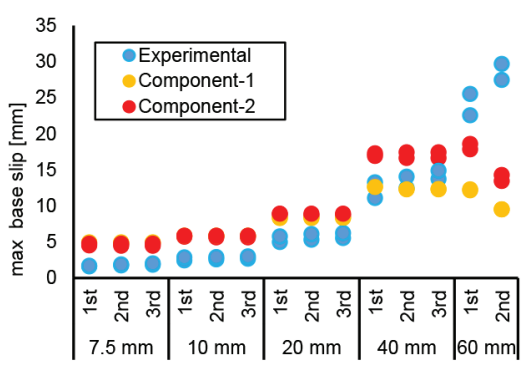

(b)

Figure 5: Results of numerical simulations compared with experimental data in terms of: (a) corner uplift and (b) base slip.

It can be observed that both numerical models predict a corner uplift higher than the experimental one. This difference increases for increasing cycle-amplitude. On the other hand, the two models overestimate the base slip only for small amplitude cycles (up to $20 \mathrm{~mm}$ ), while they underestimate the base slip for high amplitude cycles. This response may be justified considering the relative secant stiffness shown by connections in axial and lateral directions at different levels of imposed top-displacement. It is worth noting that in this work for both the component modelling approaches, the coupling effect is not accounted for, and therefore the actual relative axial-lateral secant stiffness could not be properly represented. This highlight that the coupling effect may play a crucial role for representing faithfully the local displacements, especially for high values of displacement.

\section{CONCLUSIONS}

In this work, the issue of modelling CLT shear walls was addressed in detail. In particular, the most common modelling approaches (i.e. component-level and phenomenological approaches) were taken into account and the principal aspects related to linear and non-linear analyses according to both approaches were investigated. The phenomenological approach is generally adopted by practitioners in the design process of CLT buildings due to its simplicity and reduced computational effort. Results demonstrate that shear forces and drifts are accurately captured, despite the straightforward modelling technique. On the other hand, special attention should be paid in estimation of uplift forces, generally overestimated by this approach. Moreover, a set of useful reference was given for equivalent elastic modulus for the different configurations investigated.

The component approach could be considered as the most accurate, although detailed information on the connection responses, both in elastic and inelastic field, are needed. More in-deep investigation is needed to properly capture the local displacements in the connections. Indeed, results demonstrate that an accurate representation of the coupling and friction effects need to be considered.

\section{REFERENCES}

[1] Ceccotti, A., New technologies for construction of medium-rise buildings in seismic regions: the X-lam case. Structural Engineering International, 18(2), pp. 156-165, 2008. 
[2] Ceccotti, A., Sandhaas, C., Okabe, M., Yasumura, M.,Minowa, C. \& Kawai, N., SOFIE project - 3D shaking table test on a seven-storey full-scale cross-laminated timber building. Earthquake Engineering \& Structural Dynamics, 42(13), pp. 2003-2021, 2013. https://doi.org/10.1002/eqe.2309.

[3] Hristovski, V., Dujic, B., Stojmanovska, M. \& Mircenvska, V., Full-scale shaking-table tests of X-lam panel system and numerical verification: specimen 1. Journal of Structural Engineering, 139(11), pp. 2010-2018, 2013. https://doi.org/10.1061/(ASCE)ST.1943-541X.0000754

[4] Popovski, M. \& Gavric, I., Performance of a 2-Story CLT house subjected to lateral loads. Journal of Structural Engineering, 142(4), E4015006-1-12, 2013. https://doi.org/10.1061/(ASCE)ST.1943-541X.0001315

[5] Yasumura, M., Kobayashi, K., Okabe, M., Miyake, T. \& Matsumoto, K., Full-scale tests and numerical analysis of low-rise CLT structures under lateral loading. Journal of Structural Engineering, 142(4), E4015007-1-12, 2016. https://doi.org/10.1061/(ASCE)ST.1943-541X.0001348.

[6] Flatscher, G. \& Schickhofer, G., Shaking-table test of a cross-laminated timber structure. Proceedings of the Institution of Civil Engineers - Structures and Buildings, 168(11), pp. 878-888, 2015.

https://doi.org/10.1680/stbu.13.00086

[7] Gavric, I., Fragiacomo, M. \& Ceccotti, A., Cyclic behavior of CLT wall systems: experimental tests and analytical prediction models. Journal of Structural Engineering, 141(11), 04015034-1-14, 2015.

https://doi.org/10.1061/(ASCE)ST.1943-541X.0001246

[8] Tomasi, R. \& Smith, I., Experimental characterization of monotonic and cyclic loading responses of CLT panel-to-foundation angle bracket connections. Journal of Materials in Civil Engineering, 27(6), 040141891-10, 2015. https://doi.org/10.1061/(ASCE)MT.1943-5533.0001144

[9] Gavric, I., Fragiacomo, M. \& Ceccotti, A., Cyclic behaviour of typical metal connectors for cross-laminated (CLT) structures. Materials and Structures, 48(6), pp. 1841-1857, 2015. https://doi.org/10.1617/s11527-014-0278-7

[10] Pozza, L., Massari, M., Ferracuti, B. \& Savoia, M., Experimental campaign of mechanical CLT connections subjected to a combination of shear and tension forces. Structures and Architecture Beyond their Limits, Edited by Paulo J. da Sousa Cruz, CRC Press, 2016, pp. 110-118.

https://doi.org/10.1201/b20891-13

[11] Rinaldin, G., Amadio, C. \& Fragiacomo, M., A component approach for the hysteretic behaviour of connections in cross-laminated wooden structures. Earthquake Engineering \& Structural Dynamics, 42(13), pp. 2023-2042, 2013.

https://doi.org/10.1002/eqe.2310

[12] Talledo, D., Pozza, L., Saetta, A. \& Savoia, M., Coupled shear-tension numerical model for modelling of CLT connections. XXIII World Conference. Timber Engineering, WCTE 2016, Vienna, Austria, 2016.

[13] Pozza, L. \& Scotta, R., Influence of wall assembly on behaviour of cross-laminated timber buildings. Proceedings of the Institution of Civil Engineers - Structures and Buildings, 168(4), pp. 275-286.

https://doi.org/10.1680/stbu.13.00081 
[14] Dujic, B., Strus, K., Zarnic, R. \& Ceccotti, A., Prediction of dynamic response of a 7-storey massive X-lam wooden building tested on a shaking table. Proceedings of World Conference on Timber Engineering (WCTE), Riva del Garda, Italy, 2010.

[15] Pei, S., van de Lindt, J.W. \& Popovski, M., Approximate R-factor for cross-laminated timber walls in multistory buildings. Journal of Architectural Engineering, 19(4), pp. 245-255, 2013.

https://doi.org/10.1061/(asce)ae.1943-5568.0000117

[16] Polastri, A., Loss, D., Pozza, L. \& Smith, I., CLT buildings braced with cores and additional shear walls. In proceedings of the World Conference on Timber Engineering (WCTE), 22-25 August 2016, Wien, Austria, 2016.

[17] Polastri, A. \& Pozza, L., Proposal for a standardized design and modeling procedure of tall CLT buildings. International Journal for Quality Research, 10(3), pp. 607-624, 2016. https://doi.org/10.18421/IJQR10.03-12

[18] Pozza, L., Scotta, R., Trutalli, D., Polastri, A. \& Smith, I., Experimentally based q-factor estimation of cross-laminated timber walls. Proceedings of the Institution of Civil Engineers - Structures and Buildings, 169(7), pp. 492-507, 2016.

https://doi.org/10.1680/jstbu.15.00009

[19] Pozza, L. \& Trutalli, D., An analytical formulation of q-factor for mid-rise CLT buildings - a parametric numerical analyses. Bulletin of Earthquake Engineering, 15(5), 2015-2033, 2016. https://doi.org/10.1007/s10518-016-0047-9

[20] CEN European Committee for Standardization. Design of timber structures-Part 1-1: General-Common rules and rules for buildings. Eurocode 5, CEN, Brussels, Belgium, 2009.

[21] Izzi, M., Polastri, A. \& Fragiacomo, M. Advanced modelling of CLT wall systems for earthquake resistant timber structures. INTER 2016 Meeting, 2016. Graz, Austria, Paper 49-15-6.

[22] Pozza, L., Scotta, R., Trutalli, D. \& Polastri, A., Behaviour factor for innovative massive timber shear walls. Bulletin of Earthquake Engineering, 13(11), pp. 3449-3469, 2015. https://doi.org/10.1007/s10518-015-9765-7

[23] D.M. 14.01.2008, Nuove norme tecniche per le costruzioni, G.U. 4.02.2008, n.29,

[24] CEN European Committee for Standardization. Design of structures for earthquake resistance-Part 1: General rules, seismic actions and rules for buildings. Eurocode 8, CEN, Brussels, Belgium. 2013. 